\title{
'N PAAR OPMERKINGS IN VERBAND MET DIE GEBRUIK VAN DIE EERTYDSE VERSTERKINGSBOUKUNDIGE BENAMING "DE KAT"
}

deur Kol (dr) JAN PLOEGER

This article deals with the wall or "Kat" that was erected at the Castle Cape Town, in 1691 in order to give added protection tot the bastion "Buren".

In haar destydse MA-verhandeling "Die Kasteel en ander vroeë Kaapse vestingwerke (1652-1713)" het A.C. Ras onder meer die aandag op die feit gevestig dat die onneembaarheid van die Kaapse kasteel tussen 1680 en 1685 deur sommiges in twyfel getrek is.

In die eersgenoemde jaar kon bewys word dat, nieteenstaande die hoogte van die walle tussen die bastions of bolwerke, die sogenaamde gordyne, en die bolwerke aan die kant van die berg "het pleijn van het Casteel mitsg(ade)rs: de geheele halve zijde voor gemelden berg binnen Canon schoot bloot en ontdeckt blijft ..."(1)

Aan hierdie verontrustende vermelding is die, opmerking toegevoeg dat, indien 'n aanvaller die kasteel van die kant van die berg met artillerievuur sou bestook, niemand op die plein of aan die berg se kant veilig sou wees nie. Tewens sou, as gevolg van die afwesigheid van voldoende beskutting, die bastion Buren (Buuren) nie kon verdedig word nie.

In 1685 het kommissaris-generaal H.A. van Reede, heer van Mijndregt, tydens sy inspeksiebesoek aan die Kaap heelwat meer aandag bestee aan die onbevredigende toestand waarin die kasteel verkeer het. Hy het onder meer aanbeveel om, in verband met die reeds genoemde tekortkoming, 'n dwarsmuur of kat van die bolwerk Catzenellenbogen (Catsenellenbogen) oor die plein tot by 'n punt tussen die bolwerke Oranje en Leerdam te laat bou. Deur die muur sou die plein sowel as die bolwerk (Buren) behoorlik teen artillerievuur beskerm wees. ${ }^{(2)}$

Volgens 'n handleiding vir besoekers het die dwarsmuur of kat sy verskyning in 1691 gemaak, terwyl volgens Ras met die bou in 1695 begin en die balkon, die latere nieuwe kat, in Mei van dieselfde jaar voltooi is. ${ }^{(3)}$ In dieselfde eersgenoemde publikasie is verder onder meer vermeld dat die nog bestaande muur 542 Kaapse voet lank en 39 voet hoog en onder 10 voet en bo 6 voet breed is. Rug aan rug het geboue aan weerskante van die 39-voet hoë muur verrys, terwyl in verband met die benaming kat in die eersgenoemde handleiding verklaar is: "Hierdie term word gebruik vir die muur waarop kanonne opgestel word vir verdediging."(4)

Met kat of cavalier is, in die outydse versterkingskuns, 'n verhoogde verdedigingswerk bedoel wat in ' $n$ bastion of op die vesting se wal opgerig was om vyandelike batterye te kan beheer met kanonvuur.

Hierdie beskrywing van ongeveer sewentig jaar gelede kom ooreen met die van A. Freitag in sy klassieke L'Architecture militaire (Leyde, 1635), p. 8. ${ }^{(5)}$

Volgens hierdie bronne was die kat of cavalier 'n verhoogde verdedigingswerk wat in 'n bastion of op 'n vestingwal opgerig was.

Kan hieruit afgelei word dat 'n kat tot dié besondere plekke beperk was of kon 'n kat, soos in die geval van die Kaapse kasteel, ook elders - in die besondere geval - op die binneplein opgerig word?

Die uiters beperkte getal publikasies waaroor ons beskik, laat ons nie toe om 'n antwoord op die vraag te probeer gee nie.

'n Kat was nie tot die Kaapse kasteel beperk nie. In R.L. Brohier en J.H.O. Paulusz, Land, Maps a Surveys Descriptive Catalogue of Historical Maps in die Surveyor General's Office, Col- 


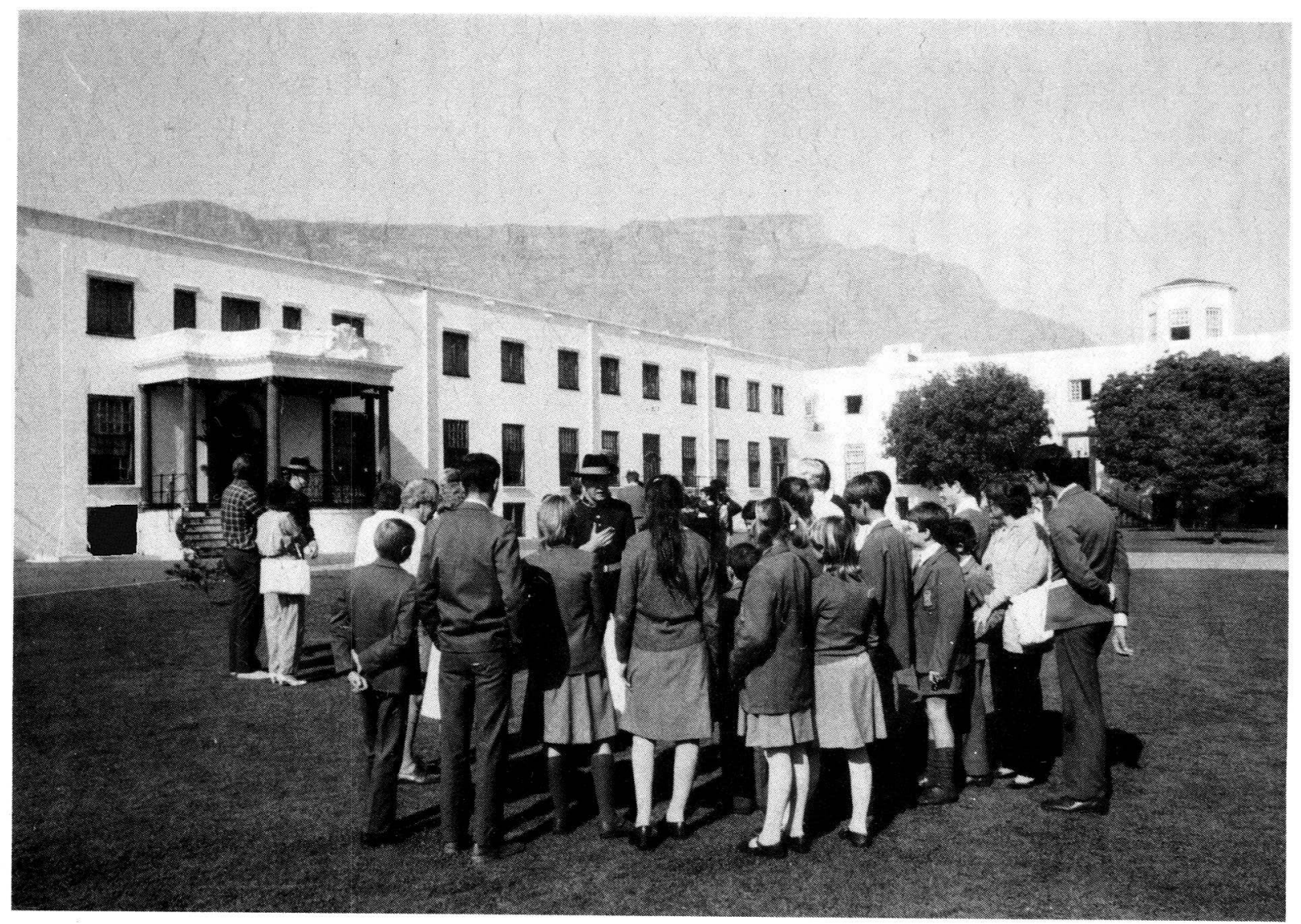

Die “kat”, Die Kasteel, Kaapstad

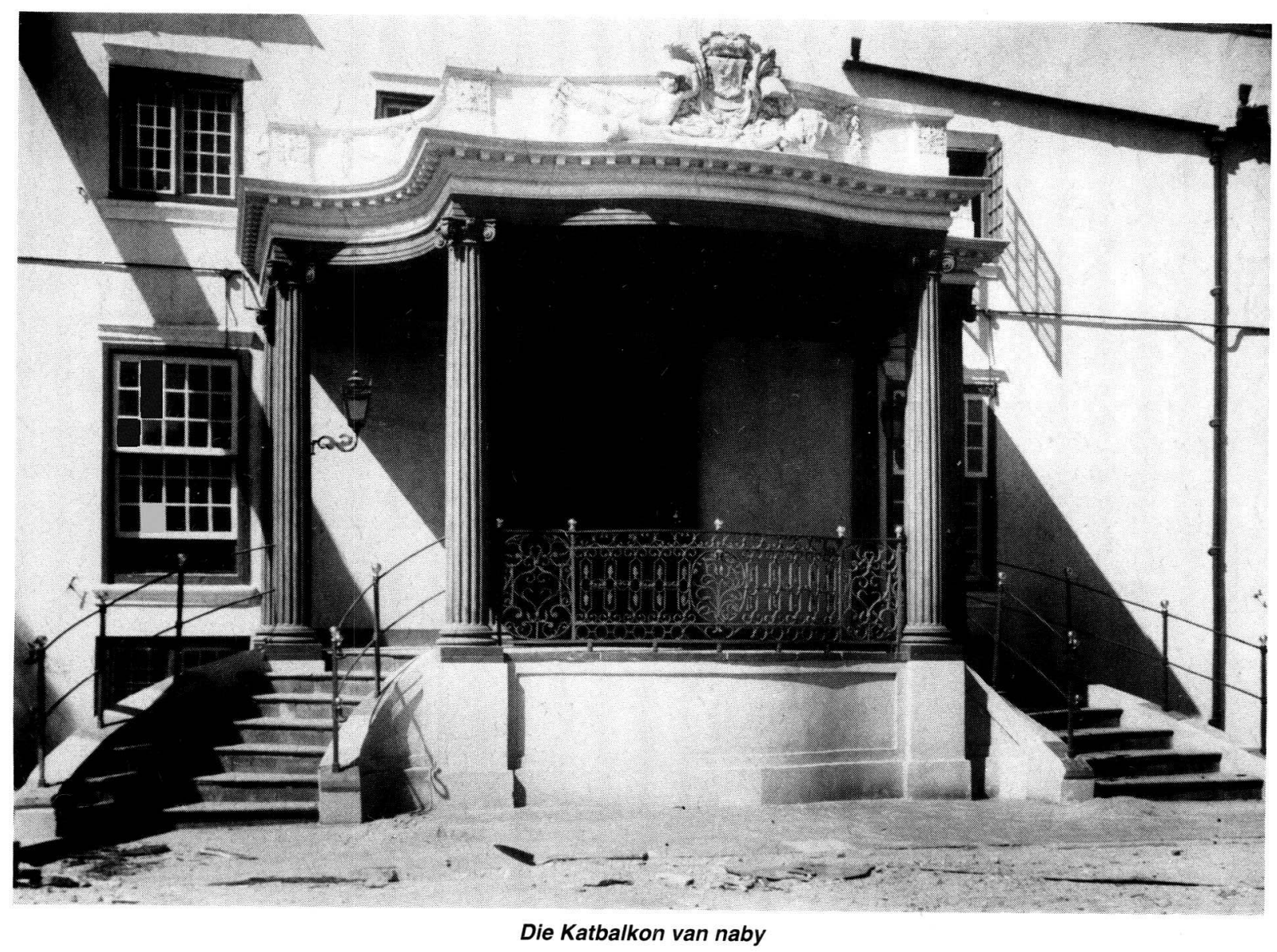


ombo, deel 2 (Colombo, 1951), is by die beskrywing van 'n Nederlandse kaart van die baai van Trincomalee, aan die ooskus van Ceylon, in die in Engels opgestelde verklaring vermeld: "Is the 'Cat'." En daarby is, deur die samestellers, aangeteken: "A mound of platform on which guns were planted."

Ongelukkig ontbreek 'n duidelike tekening van die fort by Trincomalee in die genoemde publikasie. ${ }^{(7)}$ Dit is ook die geval met ' $n$ kaart van omstreeks 1735, met 'n Nederlandse teks, van die stad Tutucorin. Onder die verklaring en verwysings wat by die ongepubliseerde kaart aangebring is, kom onder E - in vertaalde vorm "The Cat or raised battery" voor. ${ }^{(8)}$

Ten slotte ' $n$ vlugtige blik op die handelskastele en - forte van Wes-Afrika wat in 1963 op 'n meesterlike wyse deur A.W. Lawrence beskryf is. ${ }^{(9)}$

Soos bekend, het Portugese, Nederlanders, Engelse, Brandenburgers en Dene onder meer versterkte handelskantore en dies meer aan die reeds genoemde kus verower. Reeds in 1482 het die Portugese besluit om 'n kasteel by Elmina, tewete die kasteel van St George, te bou. Nederlanders het hierdie belangrike versterking in 1637 van die Portugese verower en tot 1872 beheer oor die fort en die aangrensende gebied uitgeoefen. ${ }^{(10)}$ Kort na die oordrag, in Augustus 1637, het die Nederlandse ingenieur Commersteyn die oudste bekende plan van die kasteel voltooi. ${ }^{(11)}$ Op die tekening, wat Lawrence in sy werk opgeneem het en waarvan hy die verklarings in Engels vertaal het, is onder 20 sprake van die "Yard beside the civet cats (Riverside Yard)." (12)

By die verklaring teken Lawrence in die teks aan: "At the same place is a large open space (the riverside yard (20) where many civet-cats are kept, and it is called the Cat Yard (a term later applied to any Dutch service area) $)^{(13)}$

By hierdie aanhaling kan na die volgende verduideliking van Lawrence verwys word. In die verlede, toe daar nie oorvloedig gewas is nie, was die sivetkatte van besondere belang in verband met die vervaardiging van parfuum. Sivetkatte wat in gevangeskap aangehou is, kon twee maal per week van hulle reukstof ontdoen word. $^{(14)}$

Daar was dus, soos uit die vermelde besonderhede duidelik blyk, geen verband tussen die eersgenoemde kat of cavalier en die agterplaas of terrein vir die sivetkatte, met ander woorde die Cat Yard, van die kasteel te Elmina nie.

In al die planne en sketse wat Lawrence vervaardig het, kom daar nie 'n enkele verwysing na die kat of cavalier voor nie. ${ }^{(15)}$

* Kol Dr Jan Ploeger was SSO, Argief Navorsing, SAW, 1964-1973. Staatshistorikus, RSA, 1973-1983.

\section{AANTEKENINGE}

1. MA-verhandeling (getikte en afgerolde eksemplaar), Universiteit van Stellenbosch, 1956, p 147, mitsgaders - asook. Volgens Nide Roy van Zuydewijn, Verschanste schoonheid een verrassende ontdekkingstocht langs historische verdedigingswerken in Nederland (Amsterdam 1977), p 145 (verklarende woordelys) is die Nederlandse woord gordijn dieselfde as die Franse woord courtine wat gedeelte van 'n hoofwal van 'n verdedigingswerk tussen twee bastions of bolwerke beteken. C.M. Schulten vermeld in sy proefskrif Contribution a / 'Etude des termes militaires francais en néerlandars 1567-1625 ('s-Gravenhage 1966), pp 73-74 cortine en gordine en spreek die veronderstelling uit dat die laasgenoemde woord, onder invloed van cortine, sy intrede in die Nederlandse woordeskat in die tweede helfte van die sestiende eeu gedoen het.

2. A.C. Ras, tap pp 147-148; A.J. Böeseken, Nederlandsche Commissarissen aan de Kaap 1657-1700 ('s-Gravenhage, 1938), p 91.

3. A.C. Ras, tap, p 149. Het Kasteel de Goede Hoop/The Castle of the Cape of Good Hope, p 12. Kyk ook onder meer C. van Riet Lowe en B.D. Malan, Die gedenkwaardighede van Suid-Afrika (Pretoria 1949), p 24

4. Het Kasteel, p 12. C. van Riet Lowe en B.D. Malan, tap, p 24. In J.J. Oberholster, Die Historiese Monumente van Suid-Afrika (Kaapstad 1972), p 5, verskyn die kat op 'n skets van die hand van A.A. Telford.

5. H. Zondervan (hoofred). Winkler Prins' Geïllustreerde Encyclopedie, vierde druk (Amsterdam 1918) p 408. C.M. Schulten, tap p 66 (cavailler, kavallier). Onder meer reeds vermeld deur Henricus Hondius in 1624. Volgens C.M.S. ( $p$ 66) lui Freitag se omskrywing van 1635 soos volg: ("Les cavaliers) sont des remparts eslevez sur les boulevarts desquels on peut de loing flanquer sur l'ennemy avec le canon."

6. Die in die teks genoemde publikasie, $\mathrm{p} 117$.

7. R.L. Brohier, J.H.L. Paulusz, tap plaat XLIII, teenoor p 116. Die genoemde kaart dateer van ongeveer 1760 .

8. Ibid, p 163. In Weermagswoordeboek Engels-Afrikaans (Pretoria 1954) kom op p 81 cavalier battery - verhoogde battery voor.

9. A.W. Lawrence, Trade Castles \& Forts of West Africa (London 1963)

10. Ibid. pp 103-179

11. Ibid. $\mathrm{p} 122$.

12. Ibid. p 134

13. Ibid. $p 135$

14. Ibid. 